\title{
CASO RÁPIDO \& BARATO: VAMOS ENTREGAR LOGO A ENCOMENDA?
}

\author{
Wanderson Fernandes Modesto de Oliveira² \\ Walid Abbas El-Aouar ${ }^{3}$ \\ Rodrigo José Guerra Leone ${ }^{4}$
}

http://dx.doi.org/10.1590/1413-2311.170.63509

\begin{abstract}
RESUMO
Este Caso de Ensino examina o tema da produtividade dos empregados de uma empresa privada de coleta e entrega de encomendas. A partir da constatação do aumento da demanda, dos problemas de desempenho dos empregados e das pressões para a obtenção dos resultados, o gerente de logística reflete sobre o gerenciamento da organização atual. Nesse processo, vão-se apontando elementos para análise da situação, que se evidencia com o resultado do trabalho de uma empresa de consultoria; como características do contexto, dilemas gerenciais, conflitos entre os interesses dos empregados versus os da empresa e interferências do movimento sindical, dentre outros, e que servem de fonte para um projeto de melhoria da produtividade dos empregados em uma empresa. Este estudo possibilita reflexões sobre a melhoria do processo de gerenciamento do desempenho do empregado, sendo proposto para isso: o planejamento e implantação de ações de padronização das atividades, a seleção de empregados, treinamento, avaliação do desempenho e remuneração variável de acordo com as metas alcançadas.
\end{abstract}

Palavras-Chaves: Gestão de Pessoas e Comportamento Organizacional. Produtividade. Cultura Organizacional.

\section{RÁPIDO \& BARATO: LET'S FAST DELIVER THE ORDER?}

\begin{abstract}
This Teaching Case examines the topic of employee's productivity from a private enterprise that collects and delivery orders. From the observation of increased demand, of employee's performance issues and pressures to obtain better results, the Logistics Manager reflects on the current organization management. In the process, elements for the analysis are pointed out elements, which are made evident with the support of the work of a consulting company, such as features of the context, managerial dilemmas, conflicts between the interests of employees versus those of the company and the trade union movement. These elements serve as a source for a project to improve the productivity of employees in a company. This study allows reflections on the process of performance management of temployees, being proposed for
\end{abstract}

\footnotetext{
${ }^{1}$ Recebido em 28/03/2016; aprovado em 26/05/2017.

${ }^{2}$ Universidade Potiguar - wandersonf81@gmail.com.

${ }^{3}$ Universidade Potiguar - walidbranco@gmail.com.

${ }^{4}$ Universidade Potiguar - rodrigo.leone@gestorfp.com.br.
}

REAd | Porto Alegre - Vol. 23 - No Especial - Dezembro 2017 - p. 394-411 
this: planning and implementation of actions to standardize activities, employees selection, training, benchmarking and variable remuneration according to the goals reached.

Keywords: People Management and Organizational Behavior. Productivity. Organizational Culture.

\section{CASO RÁPIDO \& BARATO: ¿LA ENCOMIENDA SE LA ENTREGAMOS PRONTO?}

\section{RESUMEN}

Este Caso para Enseñanza examina el tema de la productividad de los empleados de una empresa privada de entrega y recogida de encomiendas postales. A partir del aumento de la demanda, los problemas de desempeño de los empleados y de las presiones para la obtención de los resultados, el gerente de logística reflexiona sobre la gestión de la organización actual. En ese proceso, se señalan elementos para análisis de la situación, que se evidencia con el resultado del trabajo de una empresa de consultoría; como características del contexto, dilemas gerenciales, conflictos entre los intereses de los empleados versus los de la empresa e interferencias del movimiento sindical, entre otros, y que sirven para fomentar un proyecto de mejoría de productividad de los empleados en una empresa. Este estudio posibilita reflexiones sobre mejora el proceso de gerenciamiento del desempeño del empleado se propone para esto: planeamiento e implantación de acciones de patronización de las actividades, selección de empleados, capacitación, evaluación de desempeño y remuneración variable de acuerdo con las metas logradas.

Palabras-Clave: Gestión de Personas y Comportamiento Organizacional. Productividad. Cultura organizacional.

\section{INTRODUÇÃO}

O fim da tarde de sexta-feira se aproximava e Carlos estava ansioso e pensativo sobre as decisões que teria que tomar no início do expediente do dia seguinte. As coisas na seção de tratamento e de expedição das encomendas não estavam funcionando como deveriam. As reclamações dos clientes se avolumavam e Carlos, como gerente de logística, sabia disso.

Ele trabalha na empresa "Rápido e Barato" (R\&B), desde a sua fundação, em 2003, e começou fazendo parte da equipe que entregava as encomendas aos clientes, fossem pessoas físicas ou jurídicas, na grande Natal/RN. Desde a sua fundação, a empresa aumentou o lucro em média 5,0\% e o volume de objetos entregues cresceu 15,0\% anualmente em relação ao ano anterior, acompanhando a evolução da economia brasileira. Do seu quadro inicial de oito empregados, a R\&B ampliou para os atuais 23. Entretanto, mesmo com o aumento dos empregados, os problemas no tratamento e na entrega avolumaram-se a níveis inaceitáveis para qualquer padrão de qualidade adotado pelas melhores empresas do mesmo ramo.

REAd | Porto Alegre - Vol. 23 - No Especial - Dezembro 2017 - p. 394-411 
A R\&B contratou no ano passado uma empresa de consultoria que fez uma análise completa da empresa, apontando as necessidades de melhorias, sendo que algumas delas estavam sob a área de atuação de Carlos: "Como fazer para que as encomendas sejam tratadas e entregues com máxima rapidez e menor custo? O que terá que mudar na rotina dos empregados das seções de tratamento e de entrega? E o que fazer com a baixa produtividade e os vícios profissionais de alguns?” As empresas concorrentes agiam de modo agressivo, procurando conquistar os clientes da R\&B. Portanto, eram urgentes e imprescindíveis as decisões que Carlos teria que tomar por questão de sobrevivência e crescimento da empresa.

\section{A HISTÓRIA DA EMPRESA}

A R\&B teve início em 2003, quando José Almeida e Silvio José formaram uma sociedade e se propuseram a distribuir objetos entre empresas (móveis, equipamentos, materiais administrativos, etc.), pois, segundo eles, nesse período, “estava ocorrendo um crescimento econômico no país, refletindo no crescimento das empresas e como estas necessitavam concentrar sua energia na operacionalização de suas atividades, a coleta e a entrega de objetos entre elas poderiam ser terceirizadas”. A R\&B atuaria então neste segmento. Em um primeiro momento, a R\&B instalou-se em Natal/RN e atendia empresas localizadas na Grande Natal (Natal, Parnamirim, Macaíba e São Gonçalo do Amarante). Fazia a coleta e a entrega de objetos que não pertencessem ao monopólio postal dos Correios, tais como, encomendas, objetos sólidos ou líquidos e certos tipos de material impresso. Na sua fundação, a R\&B possuía uma equipe pequena, constituída pela (1) Área Administrativa: secretária, dois sócios, uma pessoa responsável pelo pagamento das contas e outra pelo recebimento; e pela (2) Área Operacional: coleta, tratamento e entrega dos objetos, sendo ao todo composta de três empregados.

Em 2014, existiam em Natal dez empresas que concorrem diretamente com a R\&B (sendo duas delas de grande porte e com presença em todo o país) e umas vinte e quatro que realizam atividades que apenas indiretamente concorriam, sendo a maioria transportadora de cargas rodoviárias ou que realiza transporte de mudanças domiciliares ou comerciais. $\mathrm{O}$ faturamento da R\&B foi crescente de 2003 até início de 2010, quando a crise internacional de 2008 passou a afetar seus negócios, conforme Tabela 1.

Com o seu crescimento, a partir de 2005, a empresa passou a ser mais conhecida no mercado e daí iniciou-se a procura por pessoas físicas para que a R\&B fizesse a coleta e/ou a entrega de seus objetos pessoais dentro da Grande Natal. Desse modo, com o aumento da

REAd | Porto Alegre - Vol. 23 - No Especial - Dezembro 2017 - p. 394-411 
quantidade de objetos a serem coletados, tratados e entregues, originados de empresas e de pessoas físicas, houve a necessidade de contratação de mais empregados para os atuais 23 .

Tabela 1 - Percentual de crescimento do faturamento da R\&B

\begin{tabular}{cccccccccccc}
\hline $\mathbf{2 0 0 3}$ & $\mathbf{2 0 0 4}$ & $\mathbf{2 0 0 5}$ & $\mathbf{2 0 0 6}$ & $\mathbf{2 0 0 7}$ & $\mathbf{2 0 0 8}$ & $\mathbf{2 0 0 9}$ & $\mathbf{2 0 1 0}$ & $\mathbf{2 0 1 1}$ & $\mathbf{2 0 1 2}$ & $\mathbf{2 0 1 3}$ & $\mathbf{2 0 1 4}$ \\
\hline $5 \%$ & $4,5 \%$ & $6 \%$ & $5 \%$ & $2,5 \%$ & $3,1 \%$ & $6 \%$ & $6 \%$ & $-1 \%$ & $1,2 \%$ & $3 \%$ & $1,5 \%$ \\
\hline \multicolumn{10}{c}{ Fonte: elaboração dos autores com base nos dados do estudo. }
\end{tabular}

Todavia, o crescimento do faturamento foi acompanhado, de certa forma, pelo aumento no quadro funcional, mas a produtividade dos empregados declinou em muito, gerando as reclamações e insatisfações de diversos clientes. Todas essas considerações permeiam os pensamentos de Carlos. Ele não conseguia entender que mesmo a $R \& B$ contratando mais empregados, ela continuava atrasando a entrega dos produtos.

\section{A GESTÃO DE PESSOAS}

A R\&B contratou em 2014 uma pequena empresa de consultoria (a GH Consult) para fazer um diagnóstico, e a fonte dos problemas, segundo relatório dessa consultoria, estava em falhas no processo de gestão dos empregados. A GH detectou os problemas listados abaixo que, de alguma forma, colaboravam para os problemas de atraso na entrega das encomendas, de aumento das despesas e de prejuízos acarretados ao meio ambiente.

(1) A inexistência de uma metodologia de logística estabelecida em todas as etapas do processo de coleta, de tratamento e de entrega dos objetos e a interação dela com a área de vendas e de faturamento e cobrança, objetivando a redução dos custos e o aumento da produtividade.

(2) O treinamento dos empregados para a execução dos trabalhos era realizado de maneira informal, o que ocasionava baixa produtividade.

(3) A ausência de uma política de estabelecimento de plano de trabalho, de acompanhamento e de premiação para aqueles que superam suas metas (meritocracia).

(4) Relativa incidência de impontualidade no cumprimento dos horários da jornada de trabalho sejam as do início ou as do término, o que afetava a produtividade da equipe. O que contribuía para esta situação tem relação direta com o que está descrito no segundo, terceiro e quarto parágrafos, depois do item 6.

(5) Alto percentual de absenteísmo por licença médica. Enquanto que nas empresas do mesmo ramo esse índice gira em torno de $1 \%$ ao semestre, na $\mathrm{R} \& \mathrm{~B}$ ele é de $5 \%$. Como REAd | Porto Alegre - Vol. 23 - No Especial - Dezembro 2017 - p. 394-411 
existiam muitos afastamentos de empregados, isso acarretava sobrecarga de serviço para aqueles que permaneciam trabalhando.

(6) Práticas que causam danos ao meio ambiente e aumento das despesas, tais como a inexistência da coleta seletiva do lixo, o despejo feito de copos e pratos descartáveis e de materiais plásticos em locais inadequados, lâmpadas das salas acesas quase que ininterruptamente e uso constante dos equipamentos de ar condicionados, mesmo estando sem ninguém no local.

Para complicar mais ainda o quadro apontado pela GH, Carlos tomou conhecimento que algumas torneiras estão desreguladas, ocasionando desperdício de água e quando se reuniu com a equipe e expôs essa situação, um deles chegou a externar que "quanto ao ato de ficar apagando as luzes, desligando os aparelhos de ar condicionados, recolhendo copos e pratos descartáveis, fechando torneiras de água e fazendo a coleta seletiva do lixo... que o patrão contrate mais gente, porque estou sobrecarregado de serviço e além do mais fui contratado apenas para tratar das encomendas. Essas coisas não têm nada a ver com o meu serviço".

Além dos seis itens listados anteriormente, a GH também identificou fortes influências ideológicas em alguns empregados, de modo que eles tratavam preconceituosamente os que desejam trabalhar com maior dedicação (e que exigiam dos demais) como que pertencendo ao partido das "elites exploradoras dos trabalhadores". Para o movimento sindical da categoria a prioridade são os interesses dos empregados, "esquecendo-se" dos deveres trabalhistas dos mesmos para com a R\&B. Certa vez, José da Silva externou para Carlos sua "preocupação com a ascensão do movimento sindical em todo o país, desde 2002, e as consequências para as empresas privadas", quando, segundo ele, "os empresários passaram a ser reféns dos interesses dos sindicatos, de modo que questões como produtividade, eficiência e busca pelos resultados ficaram excluídas das agendas das negociações trabalhistas.”

Ademais, a Lei n. 2012 do Governo Federal que a partir de 09/12/2012 passou a dificultar a demissão dos empregados sem justa causa, e a Lei n. 1057/2013, também do Governo Federal, por meio da qual é exigida a permanência dos empregados no quadro funcional de uma empresa que tivesse contrato com órgãos públicos federais, a não ser em caso de falta grave por parte do empregado. Ora, como $60 \%$ do faturamento da R\&B provinham de contratos com órgãos públicos federais, 35\% com empresas privadas e 5\% de pessoas físicas, Carlos sabia que os clientes públicos tinham um peso grande na receita da R\&B. Carlos concebia que, por causa dessas leis, alguns empregados da R\&B acreditam que tinham adquirido a tão sonhada estabilidade no emprego e, assim, não estariam mais zelando pelo cumprimento de suas atividades, realizando-as com baixa produtividade, já que não REAd | Porto Alegre - Vol. 23 - No Especial - Dezembro 2017 - p. 394-411 
poderiam ser demitidos por qualquer motivo.

$\mathrm{Na}$ sua mente Carlos imaginava o quadro descrito acima e as alternativas que a GH tinha apresentado no seu relatório, objetivando a redução das despesas (elas cresceram $73 \%$ acumuladamente desde 2003), a pontualidade na entrega dos produtos, o aumento das receitas (as quais cresceram acumuladamente 42,8\%, no período de 2003 até 2010) e a satisfação dos clientes (internos e externos).

\section{A PERCEPÇÃO DOS EMPREGADOS}

$\mathrm{Na}$ pesquisa realizada pela $\mathrm{GH}$ entre os empregados foi constatado que $40 \%$ deles consideram a $\mathrm{R} \& \mathrm{~B}$ um bom lugar para trabalhar e que a qualidade do relacionamento entre eles é boa, embora eles tenham enfatizado que os proprietários precisam "atentar mais para a saúde e o bem-estar do trabalhador" e que procurassem meios para contratar mais pessoas, lhes oferecer reajuste salarial acima da inflação na data base da categoria (que é em julho), um plano de saúde extensivo à família, vale alimentação e vale remédio, dentre outros benefícios. Dois empregados ligados ao sindicato comentaram com um dos consultores que "quem paga o salário deles é o patrão e não os clientes e que por isso ele tem que respeitar os direitos do trabalhador e se 'virar' para conseguir o dinheiro e atender às necessidades dos empregados".

Carlos ficava indignado que seus colegas davam mais ênfase na obtenção de mais benefícios junto à $R \& B$ do que em cumprir com suas obrigações, e que, assim fazendo, a empresa teria melhores condições financeiras para atender aos seus pleitos.

\section{A PERCEPÇÃO DOS CLIENTES}

Para $90 \%$ dos clientes, a pontualidade na entrega era a prioridade principal para suas postagens na $R \& B$, considerando-se que, segundo esses clientes, os Correios, desde a greve de 2008 , tem atrasado com muita frequência a entrega de seus objetos postais. Pela pesquisa da GH, o fator mais importante para que os clientes contratassem a R\&B era que seus objetos fossem entregues dentro dos prazos estabelecidos nos contratos, além da conservação do estado físico dos mesmos e de um bom atendimento.

\section{REFLEXÕES DE CARLOS}

Carlos ficava pensando acerca de toda essa conjuntura da $\mathrm{R} \& \mathrm{~B}$ apontada no relatório REAd | Porto Alegre - Vol. 23 - No Especial - Dezembro 2017 - p. 394-411 
da $\mathrm{GH}$, já que teria, na reunião a ser realizada no dia seguinte, que apresentar sua posposta à diretoria da empresa, a qual continha as seguintes considerações:

- as despesas da R\&B cresceram 73\% desde 2003, incluindo a contratação de mais 15 empregados (aumento de 187\% no quantitativo de pessoal);

- o volume de objetos a serem tratados e entregues aumentaram $278 \%$ no mesmo período;

- as receitas cresceram 42,8\% (entre 2003 até 2010);

- os órgãos públicos federais participam com $60 \%$ do faturamento da R\&B;

- enquanto a R\&B possuir contrato vigente com esses órgãos, ela não poderá demitir nenhum empregado, a não ser por uma irregularidade financeira cometida contra a empresa, comprovada por meio de processo administrativo;

- a influência da atuação do movimento sindical têm influenciado alguns empregados, de modo que eles passaram a realizar seu trabalho com baixa produtividade e a de focar nas relações com a $R \& B$ apenas em receber mais benefícios;

- o maior interesse dos clientes da $\mathrm{R} \& \mathrm{~B}$ é receber seus objetos nos prazos previstos nos contratos, embora os atrasos na entrega dos mesmos cheguem a $68 \%$ do total.

“Talvez a R\&B viesse a cancelar seus contratos com os órgãos públicos e demitisse aqueles empregados que não estivessem trabalhando com a produtividade necessária”, imagina Carlos. Assim, reduziria despesas de imediato e posteriormente contratasse novos empregados que não estivessem "contaminados" com as influências do movimento sindical, atacando, desse modo, as principais causas dos atrasos na entrega dos produtos. Carlos chegou a refletir sobre um processo de treinamento para as novas rotinas de logística que deverão ser implantadas na área de coleta, de tratamento e de entrega dos objetos, além da implantação do plano de metas (meritocracia). Isso fará com que os atrasos na entrega sejam eliminados ou reduzidos a um percentual aceitável. Todavia, nenhuma decisão que viesse a ser tomada escaparia da resistência interna de alguns empregados, muito menos do movimento sindical. Os embates serão intensos, prevê Carlos!

\section{NOTAS DE ENSINO}

\subsection{OBJETIVOS EDUCACIONAIS}

Este caso tem como objetivo principal conduzir os alunos a refletir sobre a seguinte REAd | Porto Alegre - Vol. 23 - No Especial - Dezembro 2017 - p. 394-411 
problemática: de um lado, as empresas necessitam para a sobrevivência e crescimento de uma maior produtividade dos seus empregados, por outro lado, os empregados têm sido influenciados por questões políticas e ideológicas e se veem como que tendo muitos direitos perante seus empregadores, já que os mesmos são tratados como "agentes de exploração econômica dos trabalhadores".

Outra questão importante que este caso objetiva é de despertar os alunos para uma análise crítica mais ampla da relação Empregador e Empregado nos tempos atuais: a) eticamente, quais as prioridades que devem prevalecer numa organização: aquelas que se referem aos dos direitos dos empregados ou os da empresa? b) os empregadores devem atentar para conceder mais direitos aos seus empregados (melhores salários, plano de benefícios, etc.), mais do que os empregados para com os direitos de seus empregadores (dedicação, produtividade, eficiência, etc.)? c) é correto premiar aqueles empregados que se dedicaram mais, produziram mais e melhor, superando suas metas de trabalho, diferenciandoos daqueles que não atingiram suas metas e que por isso não receberão nenhuma premiação?

\subsection{FONTES DOS DADOS}

A construção do caso realizou-se a partir de vivências dos autores em determinadas empresas, sendo o caso ficcional, bem como as citadas leis. Todavia, a ambientação caracteriza uma empresa específica e circunstâncias reais. Os dados primários foram coletados por meio da observação e de entrevistas realizadas com os gestores e os 11 empregados da R\&B. Foram escolhidos aqueles que realizam as atividades que estão diretamente relacionadas com a coleta, tratamento e a entrega das encomendas. Nas entrevistas, foram utilizadas questões semiestruturadas, sendo realizadas de 11 a 15/03/2014 na própria empresa e também com os responsáveis pela consultoria executada pela GH. Foram entrevistados os dois consultores dessa empresa responsáveis por todo o trabalho de consultoria realizado para a $\mathrm{R} \& \mathrm{~B}$. Nas entrevistas, foi utilizado um roteiro semiestruturado, tendo sido aplicado no dia 16/03/2013 nas dependências da GH. Para garantir a veracidade e fidelidade das informações, todas as pessoas que foram objeto de entrevista autorizaram sem restrições a publicação do caso.

\subsection{BREVE REFERENCIAL TEÓRICO}

A $R \& B$ é o caso de uma empresa privada que desenvolve uma atividade em que a REAd | Porto Alegre - Vol. 23 - No Especial - Dezembro 2017 - p. 394-411 
questão da entrega dos produtos no menor espaço de tempo é o fator mais importante para seus clientes e que quanto maior o percentual de pontualidade na entrega, mais satisfação eles terão e, consequentemente, o retorno financeiro para a $R \& B$ será maior.

Por ser uma empresa privada, a $R \& B$ necessita gerar riqueza para seus proprietários de modo a garantir sua sobrevivência e crescimento, principalmente num mercado competitivo e, em razão dos efeitos da globalização, a administração das organizações tornou-se ainda mais complexa, sendo indispensável que elas sejam competitivas para enfrentarem esses desafios (PORTER, 2008; PRAHALAD; HAMEL, 2005). As vantagens competitivas sustentáveis de uma organização são aquelas que os concorrentes não podem comprar, se apropriar ou copiar (WAGNER; HOLLENBECK, 2015). Elas possibilitam que uma organização ofereça produtos e serviços melhor do que os concorrentes ou, pelo menos, fazê-las iguais, mas a um custo estruturalmente menor (HITT; MILLER; COLELLA, 2006; VAN DER HEIJDEN, 2011).

Ehrahdt e Brigham (2012) afirmam que na maior parte dos investimentos, uma empresa gasta dinheiro no presente com a expectativa de ganhar mais dinheiro ainda no futuro e, alinhado com essa expectativa, a R\&B espera que seus empregados assimilem que foram contratados prioritariamente para a geração dessa riqueza, dentre outras eventuais razões pessoais, ideológicas ou organizacionais (GITMAN, 2011). Mas, para que isso ocorra, a empresa necessita elaborar e executar um planejamento financeiro de longo prazo que inclui planos estratégicos, operacionais e previsão de vendas (EHRHARDT; BRIGHAM, 2012). Ou seja, nenhuma empresa crescerá "naturalmente" num mercado competitivo. Todos seus empregados precisam canalizar seus melhores esforços para que conjuntamente a organização atinja seus objetivos e metas (lucros, vendas, redução de despesas, aumento do Market Share, dentre outros).

Pelo segmento de atuação (coleta e entrega de bens entre empresas), a questão da utilização de tecnologia de ponta não é o fator mais importante, mas sim uma eficaz e eficiente gestão dos empregados. Para a Administração, eficácia e eficiência não são a mesma coisa. A eficácia é definida como a capacidade de obtenção do recurso e refere-se a um nível absoluto de realização dos resultados (OSTROFF; SCHMITT, 1993); enquanto que a eficiência é a medida de quão bem os recursos gastos são utilizados (FUGATE; MENTZER; STANK, 2010). Para Snell e Bohlander (2013), a ideia de que as empresas "competem por meio das pessoas" dá ênfase ao fato de que o sucesso depende cada vez mais na capacidade empresarial de gerenciar o capital humano, o qual se relaciona com os recursos humanos dentro de uma organização, que incluem o conhecimento tácito, habilidade, atitude e 
experiência dos empregados (KAMUKAMA, 2013).

Segundo Syverson (2011), produtividade é a eficiência na produção e é, literalmente, uma questão crucial para a sobrevivência das empresas. Quanto à baixa produtividade de alguns empregados da R\&B, de acordo com Longenecker, Moore e Petty (2007), o desempenho dos empregados pode ser melhorado por meio de treinamento adicional. A R\&B precisa então padronizar as rotinas de trabalho (objetivando torná-las mais produtivas), treinar os empregados para executá-las da maneira que a situação requer, avaliá-los periodicamente objetivando melhorar o desempenho dos mesmos e premiar aqueles que geram melhores resultados para a empresa (meritocracia), considerando-se que, segundo Sharma e Bajpai (2011), a insatisfação com a remuneração pode levar à diminuição da satisfação com o trabalho, à desmotivação, ao baixo desempenho e ao aumento do absentismo. Almer, Bertolini e Higgs (2013) ampliam o entendimento da relação entre salário e desempenho do empregado, quando sugerem que a satisfação é correlacionada com percepções de equidade e justiça em torno de salário (meritocracia) e não apenas com o seu valor nominal isoladamente.

A avaliação de desempenho cumpre um importante papel organizacional, indicando o que será avaliado, direcionando o método de realização do trabalho, normatizando mecanismos adequados para a avaliação, apresentando os objetivos a serem alcançados, apontando formas de comunicação dos resultados e alternativas de monitoramento, sugerindo investimento em desenvolvimento individual e vinculando resultados apurados à recompensa (SILVA; LUZ, 2010; ST-ONGE, et al, 2009). A necessidade e os benefícios da avaliação de desempenho dos empregados também são ressaltados por Lucena (1995), quando descreve seus três principais objetivos: (1) definir o grau de contribuição de cada empregado na geração da riqueza para a empresa; (2) promover o autodesenvolvimento deles; e (3) oferecer subsídios para fins de remuneração, tendo como princípio a meritocracia.

A política da meritocracia favorece os empregados que se empenham em realizar o seu trabalho com máxima dedicação, de modo que a empresa obtenha os resultados esperados por parte deles. Isso cria uma distinção entre empregados quanto a sua remuneração, pois ela se torna variável de acordo com a sua produtividade. Weng, et al (2010) depararam com relações positivas entre as práticas de remuneração e o comprometimento dos empregados.

Para Dondoni e Detoni (2010), recompensas como ganhos compartilhados, bônus baseados em metas, participação nos lucros e participação acionária serão cada vez mais impetradas no desempenho organizacional e de equipe. Segundo esses autores, práticas como basear a dimensão do mérito no desempenho da equipe, e impulsionar o próprio trabalhador a determinar o pagamento do mérito individual, incentivam a cooperação e o desempenho, 
embora, por outro lado, Nahai (2013) chama a atenção de que a meritocracia tem um viés elitista na medida em que prioriza a excelência, mesmo no detrimento da justiça social, pois deixa de oferecer o prêmio pelos resultados igualitariamente a todos os participantes do processo produtivo.

Uma alternativa que pode ser considerada é a renovação do quadro de empregados da $\mathrm{R} \& \mathrm{~B}$, por meio de novas contratações e/ou de demissões daqueles que não estão dispostos a contribuir com seu trabalho (individual e coletivo) para a geração de riquezas, uma vez que para desenvolver a competitividade, as empresas necessitam contratar profissionais com as competências necessárias à execução do trabalho alinhado com seus objetivos organizacionais (BREAUGH, 2008; KRAUTER; SOUSA, 2009). Para Fleury e Fleury (2011), competência é um saber agir que implica mobilizar, integrar, transferir conhecimentos, recursos e habilidades que agreguem valor econômico para a organização e valor social ao indivíduo.

Para melhorar a sua competitividade a empresa pode necessitar também de realizar a demissão daquelas pessoas que não estão trabalhando (e nem se dispõem) com a produtividade necessária para o cargo. De acordo com Lacombe (2005, p. 99), "Tão importante quanto admitir as pessoas certas nos momentos certos e demitir as pessoas no momento em que se torna necessário. [...] O erro mais frequente e grave é conviver muito tempo com pessoas que produzem pouco". Foi apontada pela empresa de consultoria a indisciplina de alguns empregados na $\mathrm{R} \& \mathrm{~B}$ tem ocasionado prejuízos principalmente na entrega dos objetos e no faturamento. Quanto a este problema, Milkovich e Boudreau (2000) indicam quatro elementos que são imprescindíveis na composição de um sistema disciplinar, de modo que os empregados sejam norteados na execução de sua rotina de trabalho e os auxiliem no alcance de suas metas: (1) estabelecer as regras; (2) comunicar as regras a todos os empregados; (3) avaliar periodicamente o comportamento deles; (4) aplicar as ações disciplinares previstas visando à mudança do comportamento dos empregados.

No que se refere a um eventual conflito ideológico com o sindicato, por causa das mudanças que a R\&B necessita implementar, por questão de assegurar seu crescimento (treinamentos, avaliação de desempenho, meritocracia, etc.), Longenecker, Moore e Petty (2007), sugerem que as políticas de recursos humanos claras e bem disseminadas, a empresa pode minimizar a probabilidade de conflitos trabalhistas internos e/ou contribuir para relações saudáveis com o sindicato.

\section{ROTINAS DE TRABALHO NÃO PADRONIZADAS}

REAd | Porto Alegre - Vol. 23 - No Especial - Dezembro 2017 - p. 394-411 
Os processos de coleta, de tratamento e da entrega dos objetos e o intercâmbio deles com os sistemas utilizados nas áreas financeira e comercial têm sido realizados de modo ainda improvisado. Não há uma metodologia técnica estabelecida que guiem esses processos de modo que os mesmos sejam executados com um menor custo, maior rapidez e produtividade. Quando um novo empregado é contratado, ele aprende dos mais antigos as tarefas a serem realizadas e as repete no seu trabalho.

Por outro lado, o financeiro da $R \& B$ não tem um controle total dos seus custos e nem se o que foi coletado e entregue foi corretamente faturado ou cobrado para seus clientes ou sobre a inadimplência destes. Segundo Lemes, Cherobim e Rigo (2010), a cobrança é o ato de efetivação do recebimento dos valores das vendas, à vista ou a prazo e de forma oportuna. De acordo com esses autores, o processo de cobrar é tão importante quanto o de vender, uma vez que o ciclo operacional só finaliza quando o valor da venda é recebido pela empresa. Em outras palavras, a R\&B necessita aprimorar tanto seus atuais processos de coleta, de tratamento e de entrega dos objetos, como também se os mesmos estão sendo faturados corretamente ou cobrados, para que a saúde financeira da empresa seja preservada.

A área comercial não faz também uma gestão mais acurada sobre sua atual carteira de clientes (quem, o quê e quando contrata e o que tem potencial para ser atendido pela $R \& B$ ) ou sobre a prospecção de novos clientes. Os novos clientes são aqueles que têm "procurado" a $\mathrm{R} \& \mathrm{~B}$, e, na maior parte dos casos, por iniciativa deles.

\section{QUESTÃO AMBIENTAL}

A preocupação pela conservação do meio ambiente e utilização racional dos recursos naturais, conforme pode se observa pelos comentários de um dos empregados na reunião com Carlos (item 6 da Seção: Gestão de Pessoas), é superficial, pois, deduz-se que eles veem essas questões como sendo da exclusiva responsabilidade dos patrões. Todavia, Kuhlman e Farrington (2010) afirmam que a sustentabilidade está atenta ao bem-estar das gerações futuras e, em particular, aos insubstituíveis recursos naturais, em oposição à cultura capitalista de se buscar a satisfação das necessidades presentes. Para isso, Loureiro (2013) sugere que todos os membros de uma organização sejam:

1. Conscientizados dos custos gerados para a empresa, para os empregados e para a sociedade, decorrentes dos prejuízos causados ao meio ambiente, e pela má utilização dos recursos naturais.

2. Apresentados os ganhos que a empresa, os empregados e a sociedade terão quando é REAd | Porto Alegre - Vol. 23 - No Especial - Dezembro 2017 - p. 394-411 
realizada uma eficiente gestão da sustentabilidade.

3. Incentivados a participar com sugestões de melhorarias do cuidado com o meio ambiente e com a utilização dos recursos naturais e premiados aqueles que efetivamente contribuíram com ações com essas finalidades.

\section{SUGESTÕES PARA DISCUSSÃO DO CASO}

Este caso poderá ser lido em 30 minutos em sala de aula. Sugere-se sua aplicação em cursos de graduação e pós-graduação na área de administração. A metodologia deverá iniciar: a) discussão sobre as questões relacionadas com os conflitos entre o interesse pessoal do empregado versus objetivos da empresa e as influências ideológicas dos movimentos sindicais (os aspectos negativos e os positivos para a empresa); b) leitura individual e discussão em pequenos grupos; c) levantamento de soluções para as situações problema; d) discussão das alternativas em plenária; e) fechamento com orientações conceituais e procedimentais pelo professor.

$\mathrm{Na}$ condução deste caso, deve-se focar a discursão no equilíbrio da relação entre direitos e obrigações, dos empregados e empregadores, e os problemas resultantes desse desequilíbrio para com os clientes. Uma sugestão para a preparação dos alunos é dividir a sala em dois grupos, quando cada um ficará responsável pela análise de acordo com um ponto de vista: a do empregador e a do sindicato dos empregados. Uma proposta para a direção do caso é discutir as seguintes questões:

- Considerando-se a atuação forte do movimento sindical na $R \& B$, quais as características que podem ser observadas no comportamento dos empregados que têm ocasionado os atrasos na entrega dos objetos?

- Indique os fatores culturais e administrativos da R\&B que contribuem para os atrasos citados no item anterior.

- Relacione as alternativas de ação mais apropriadas a serem aplicadas na R\&B objetivando a resolução dos problemas dos atrasos nas entregas dos objetos.

- Na relação Empregador e Empregado: (1) os empregadores devem atentar mais para as expectativas dos seus empregados, tais como melhores salários e benefícios (plano de saúde, vale alimentação, etc.), (2) do que estes em atender os compromissos acordados com seus empregadores na assinatura do contrato de trabalho (dedicação, produtividade, eficiência, etc.)? Qual dessas duas situações favorece a competitividade 
da empresa?

- É correto: (1) premiar aqueles empregados que produzir mais e melhor, superando suas metas de trabalho e, (2) aqueles que não atingiram suas metas não receberem nenhuma premiação? Se acontecer a premiação, isso não seria considerado uma injustiça já que todos em uma empresa devem ser tratados igualmente (na visão dos sindicatos)? E se todos (quer tenham atingido ou não as metas de trabalho) receberem a mesma premiação, isso não desestimularia quem se esforçou para produzir os resultados esperados?

- Seria correto, em um ambiente de concorrência globalizada, incentivar o comprometimento dos empregados e dos patrões com questões ambientais, considerando que aqueles já estão sob intensa pressão para produzirem os resultados e estes têm gastos elevados na gestão das empresas (custos de mão de obra, de máquinas e equipamentos, impostos, tributos, energia elétrica, manutenção de veículos e segurança, dentre outros)?

\subsection{CONTEXTUALIZAÇÃO TEÓRICA E ANÁLISE DO CASO}

Para a questão 1, inicialmente, poderão ser analisados os problemas identificados pela GH e listados nos itens 1 a 5 da Seção "A gestão de pessoas". A contextualização pode se iniciar com o papel realizado pelos sindicatos junto às categorias dos empregados e à classe empresarial, buscando identificar as principais reinvindicações auferidas nas três últimas negociações coletivas, bem como qual foi o modus operandi deles dentro das empresas e as consequências: (1) houve aumento da produtividade dos trabalhadores?; (2) as empresas obtiveram os resultados planejados em decorrência da assinatura dos acordos coletivos (crescimento das vendas e do lucro, redução das despesas, aumento do Market Share, melhoria da qualidade dos produtos e serviços, redução dos impactos no meio ambiente, clima organizacional satisfatório, dentre outros)? Pode-se aprofundar essa contextualização utilizando-se os trabalhos de Macedo (2012), que discorre sobre o que é produtividade, como mensurá-la e propõe alternativas para melhorá-la; o de Boito e Marcelino (2010), os quais expõem o histórico do movimento sindical no Brasil na década de 2000 e as principais conquistas obtidas nas negociações coletivas; e o de Longenecker, Moore e Petty (2007), os quais propõem meios de serem minimizados os conflitos entre empregados e entre os empregadores e os sindicatos.

Em relação à questão 2, conforme descritos nos itens 1 a 3 da Seção "A gestão de REAd | Porto Alegre - Vol. 23 - No Especial - Dezembro 2017 - p. 394-411 
pessoas", alguns fatores poderão ser identificados. O trabalho de Gitaman (2011) sugere respostas à questão relacionada com a contratação de um empregado na expectativa da geração de riqueza para o seu empregador. No que se refere à baixa produtividade, o estudo de Longenecker, Moore e Petty (2007) aponta as formas de melhorá-la por meio de treinamento e, por sua vez, Weng, et al (2010) discorrem sobre a relação entre a remuneração e o comprometimento dos empregados.

Quanto à questão 3, a indisciplina de alguns empregados foi apresentada pela GH como uma das causas do atraso na entrega dos objetos. Para o tema da demissão do trabalhador que não está (e que nem se dispõe) a produzir os resultados da empresa, o trabalho de Lacombe (2005) fornece uma fundamentação aplicável a essa situação, e Milkovich e Boudreau (2000) indicam os elementos necessários para a composição de um sistema disciplinar e os seus benefícios para as empresas, empregados e clientes.

No que se refere à questão 4, Breaugh (2008) e Krauter e Sousa (2009) destacam a importância de as empresas em só contratarem profissionais com as competências necessárias à execução do trabalho, desde que este estejam alinhados com seus objetivos organizacionais. Para o estudo sobre a competitividade das organizações, os estudos de Hitt, Miller e Colella (2006), Porter (2008), Van Der Heijden (2011) e Wagner e Hollenbeck (2015) são obras de referência.

Para a questão 5, Weng, et al (2010) abordam o tema da meritocracia, vinculando os fatores: (a) remuneração variável, com (b) metas atingidas e a atração de empregados para o (c) comprometimento com os resultados da empresa.

Quanto à questão 6, Kuhlman e Farrington (2010) e Loureiro (2013) discorrem sobre a importância e os benefícios da sustentabilidade para as empresas e sociedade, sendo que o aparente aumento dos custos de uma organização ao adotar práticas sustentáveis, eles serão absorvidos com outros ganhos obtidos a médio e longo prazo.

O caso possibilita, ainda, que os alunos de ambos os grupos possam ponderar seus argumentos sob a perspectiva do outro, levando-os a verem seus eventuais "pontos cegos" nas premissas defendidas. Deve ser chamada a atenção que não há uma resposta certa, bem como para o aprendizado adquirido por meio da construção de linhas de argumentos decorrente dos debates e da leitura crítica do referencial apontado para as pesquisas.

\section{REFERÊNCIAS}

ALMER, E., D.; BERTOLINI, M.; HIGGS, J. A model of individual accounting faculty REAd | Porto Alegre - Vol. 23 - No Especial - Dezembro 2017 - p. 394-411 
salaries. American Accounting Association, v. 28, n. 3, p. 411-433. 2013.

BOITO Jr., A.; MARCELINO, P. O sindicalismo deixou a crise para trás? Um novo ciclo de greves na década de 2000. Caderno CRH, v. 23, n. 59, p. 323-338. 2010.

BRASIL. Lei $n^{\circ}$ 2012, de 09 de dezembro de 2012. Dispõe sobre a demissão de empregados. Diário Oficial [da] República Federativa do Brasil, Ministério do Trabalho e Emprego, Brasília, DF, 10 dez. 2012.

BRASIL. Lei n. 1057, de 10 de junho de 2013. Dispõe sobre a permanência de empregados que prestam serviços aos Órgãos Públicos Federal. Diário Oficial [da] República Federativa do Brasil, Ministério do Trabalho e Emprego, Brasília, DF, 11 jun. 2013. BREAUGH, J. A. Employee recruitment: current knowledge and important areas for future research. Human Resource Management Review, v. 18, n. 3, p. 103-118. 2008.

DONDONI, P. C.; DETONI, T. L. A gestão e a mensuração de desempenho: onde está o indivíduo? Revista TECAP, v. 2, n. 2, p. 27-31. 2010

ERHARDT, M.C.; BRIGHAM, E.F. Administração financeira: teoria e prática. 2. ed. São Paulo: Cengage Learning, 2012.

FLEURY, A.; FLEURY, M. T. L. Estratégias empresariais e formação de competências. 3. ed. São Paulo: Atlas. 2011.

FUGATE, B. S., MENTZER, J. T., \& STANK, T. P. Logistics performance: efficiency, effectiveness, and differentiation. Journal of Business Logistics, v. 31, n. 1, p. 43-62. 2010. GITMAN, L. J. Financial management principles (13th ed.). New York: Pearson Prentice Hall. 2011.

HITT, M. A.; MILLER, C. C.; COLELLA, A. Organizational behavior: a strategic approach. Hoboken (NJ): John Wiley \& Sons. 2006.

KAMUKAMA, N. Intellectual capital: company's invisible source of competitive advantage. International Business Journal, v. 23, n. 3, p. 260-283. 2013.

KRAUTER, K.; SOUSA, A. F. de. The relationship between executives' remuneration and corporate financial performance. International Review of Business Research Papers, v. 5, n. 1, p. 163-173. 2009.

KUHLMAN, T.; FARRINGTON, J. What is sustainability? Sustainability, v. 2, p. 34363448. 2010.

LACOMBE, F. J. M. Recursos humanos: princípios e tendências. São Paulo: Saraiva. 2005. LEMES, A. B. J.; CHEROBIM, A. P. M. S.; RIGO, C. M. Administração Financeira: princípios, fundamentos e práticas brasileiras. Rio de Janeiro: Elsevier. 2010. LONGENECKER, J. G.; MOORE, C. W.; PETTY, J. W. Administração de pequenas REAd | Porto Alegre - Vol. 23 - No Especial - Dezembro 2017 - p. 394-411 
empresas. São Paulo: Cengage Learning. 2007.

LOUREIRO, C. F. B. Sustentabilidade e educação: um olhar da ecologia política. São Paulo: Cortez. 2013.

LUCENA, M. D. S. Avaliação de desempenho. São Paulo: Atlas. 1995.

MACEDO, M. M. Gestão da produtividade nas empresas. Revista Organização Sistêmica, v. 1, n. 1, p. 110-119. 2012.

MILKOVICH, G. T.; BOUDREAU, J. W. Administração de recursos humanos. São Paulo: Atlas. 2000.

NAHAI, R. N. Is meritocracy fair? A qualitative case study of admissions at the University of Oxford. Oxford Review of Education, v. 39, n. 5, p. 681-701. 2013.

OSTROFF, C.; SCHMITT, C. Configurations of organizational effectiveness and efficiency. Academy of Management Journal, v. 36, n. 6, p. 1345-1361. 1993.

PORTER, M. E. Competitive strategy: techniques for analyzing industries and competitors. New York (NY): Free Press. 2008.

PRAHALAD, C. K.; HAMEL, G. Competing for the future (2nd ed). Boston: Harvard Business School Press. 2005.

SHARMA, J., P.; BAJPAI, N. Salary satisfaction as an antecedent of job satisfaction: development of a regression model to determine the linearity between salary satisfaction and job satisfaction in a public and a private organization. European Journal of Social Sciences, v. 18, n. 3 , p. $450-461.2011$.

SILVA, L. V.; LUZ, T. R. Gestão por competências: um estudo dos impactos gerados na avaliação de desempenho e remuneração. GES - Revista Gestão e Sociedade

CEPEAD/UFMG, v. 4, n. 8, p. 539-561. 2010.

SNELL, S.; BOHLANDER, G. Administração de recursos humanos. São Paulo: Cengage Learning. 2013.

ST-ONGE, S. et al. Managers' motivation to evaluate subordinate performance. Qualitative Research in Organizations and Management: An International Journal, v. 4, n. 3, p. 273 $-293.2009$.

SYVERSON, C. What determines productivity? Journal of Economic Literature, v. 49, n. 2, p. 326-365. 2011.

VAN DER HEIJDEN, K. Scenarios: the art of strategic conversation. Chichester \& New York: John Wiley \& Sons. 2011.

WAGNER III, J. A.; HOLLENBECK, J. R. Organizational behavior: securing competitive advantage (2nd ed.). New York (NY): Routledge. 2015.

REAd | Porto Alegre - Vol. 23 - No Especial - Dezembro 2017 - p. 394-411 
WENG, Q. et al. The relationship between career growth and organizational commitment.

Journal of Vocational Behavior, v. 77, v. 3, p. 391-400. 